\title{
PARTICIPAÇÁO POLÍTICA POR MEIO DO MOVIMENTO FEMINISTA COMO FORMA DE CONTROLE SOCIAL E EFETIVAÇÃO DA JUSTIÇA SOCIAL DE GÊNERO
}

\author{
POLITICAL PARTICIPATION THROUGH THE FEMINIST MOVEMENT AS \\ A FORM OF SOCIAL CONTROL AND IMPLEMENTATION OF GENDER \\ SOCIAL JUSTICE
}

\author{
Fernanda Caroline Alves de Mattos ${ }^{\mathrm{I}}$ (1) \\ Renato Bernardi ${ }^{\mathrm{II}}$ (i)
}

\begin{abstract}
${ }^{\text {I } U n i v e r s i d a d e ~ E s t a d u a l ~ d o ~ N o r t e ~}$ do Paraná, Jacarezinho, PR, Brasil. Mestranda em Ciência Jurídica. E-mail: mattos.fernandac@gmail.com
\end{abstract}

${ }^{\text {II } U n i v e r s i d a d e ~ E s t a d u a l ~ d o ~ N o r t e ~ d o ~}$ Paraná, Jacarezinho, PR, Brasil. Doutor em Direito. E-mail: bernardi@uenp.edu. br

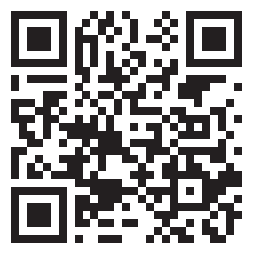

DOI: http://dx.doi.org/10.31512/rdj.v21i39.312

Recebido em: 09.10.2019

Aceito em: 20.10.2020
Resumo: $O$ presente trabalho busca analisar como a participação popular no movimento feminista é um formato de controle social das atuaçóes estatais e ferramenta de implementação de direitos das mulheres e desenvolvimento de uma justiça social. Para isso foi analisado o que é o controle social e como a existência de movi-mentos sociais se consubstancia num seu efetivo exemplo democrático. Em seguida verificou-se que o mo-vimento feminista é um modelo nessa prática, na medida em que luta para efetivar, criar e defender direitos das mulheres. E, por fim, apontase sua capacidade de controle e mudanças sociais para além das normas e políticas implementadas. Compreendendo os movimentos abraçados por mulheres como ferramenta de transformação social e resolução eficaz de desigualdades estruturadas. $\mathrm{O}$ método utilizado foi o dedutivo por meio de revisão bibliográfica e documental.

Palavras-chave: Controle social. Participação política. Movimento feminista.

\begin{abstract}
This paper seeks to analyze how popular participation in the feminist movement is a format of social control of state actions and a tool for implementing women's rights and developing social justice. To this end, we analyzed what social control is and how the existence of social movements is embodied in their effective democratic example. The feminist movement was then found to be a model in this practice, as it struggles to implement, create and defend women's rights. And, finally, its capacity for control and social change is pointed beyond the implemented norms and policies. Understanding the movements embraced by women as a tool for social transformation and effective resolution of structured inequalities. The method used was deductive through bibliographic and documentary review.
\end{abstract}

Keywords: Social control. Political participation. Feminist movement. 


\section{Consideraçóes iniciais}

O presente artigo tem por escopo analisar de que forma a participação política da mulher por meio do movimento feminista funciona como um controle social, desde cobranças ao Estado para garantia de direitos fundamentais femininos, até a efetiva realização de uma justiça social de gênero que interfira nas raízes das desigualdades sociais.

A pesquisa abordada se justifica uma vez que é possível observar desigualdades latentes entre os diversos atores sociais, bem como enxergar a força que os movimentos sociais, em especial no feminista, têm para a realização de controle e resolução das exclusôes de direito em face das diversidades.

Inicialmente busca-se definir o controle social e de que forma, considerando a movimentaçáo de atores sociais de forma organizada, ele poder ser um meio de, náo só de fiscalização - função basilar dos controles realizados em face do Estado - mas de luta por reconhecimento de direitos sociais.

Compreendendo assim como o formato dos movimentos sociais se consubstanciam numa efetiva participação popular que se adequa aos princípios e condições constitucionais para efetivação da democracia.

A partir disso, especificando-se a análise realizada, traz-se a postura do movimento feminista em si, como uma forma não só de luta, mas ferramenta de alcance de poder para cobrar e controlar a atividades que firam seus direitos ou não os garanta.

E assim, considerando as possibilidades dadas pela existência e resistência do movimento, por meio de suas diversas pautas e subgrupos relacionados, explicitar a capacidade de modificação de paradigmas patriarcais instaurados social e institucionalmente, por meio de ações que reconheçam o protagonismo feminino, como forma de desenvolvimento da mulher e de toda sociedade

Para tanto, foi utilizado método dedutivo de abordagem, partindo do ponto geral que é o controle social exercido pela participação popular em movimentos sociais, para o específico que aqui se trata das possibilidades dadas pelo movimento feminista de controle para efetivaçáo de direitos e mudanças sociais, tomando como suporte procedimental a revisáo bibliográfica e documental.

\section{Controle social e participação popular como uma forma de busca pela efetivação de direitos e mudança social}

Pode-se conceituar o controle social como espécie de controle a ser realizado em face da administração pública que é realizado pela sociedade em face do Estado nas atividades que este realiza. Sua importância se destaca em face dos controles institucionais, isto é, os realizados pelos 
três poderes constituídos por se comportar como um exemplo de representação da essência de uma democracia participativa. Juarez Freitas (2009, p. 402) afirma, nesse sentido que:

$o$ controle da sociedade [é] o exercício do direito fundamental de, preferencialmente em movimentos sociais. exercer a fiscalização popular e direta da atividade pública lato sensu quanto à eficiência e à eficácia dos ditames estabelecidos pela Constituição (FREITAS,2009, p. 402). (grifo nosso)

Esse exercício se fundamenta como direito fundamental por estar plenamente amparado no texto constitucional na medida em que se defende o princípio da participaçáo previsto no parágrafo único do art. $1^{\circ}$ da Constituição ${ }^{1}$. De forma que a pretensa defesa desse princípio se vê justificada pela necessidade conquistar uma verticalização inclusiva entre a atuação do controle realizado pela sociedade e a daqueles que exercem o poder político estatal (FREITAS, 2009, p. 405).

Dessa forma, é um direito fundamental protegido na essência principiológica constitucional, e por isso deve ser reconhecido como forma, inclusive, de proteção da dignidade de quem lhe aprouver (SARLET, 2012, p. 102).

Além disso, é um modo de consubstanciação da democracia participativa, que também pode ser considerada como um direito fundamental, ao mesmo tempo em que é condição de sua fundamentalidade. Uma vez que é mediante sua plena existência, que valores como a própria democracia, aqui trazida como significante da igualdade, e a liberdade, são postuladas ${ }^{2}$ (ALVES, 2013, p. 252).

Para além de um direito formal abstrato, o controle social pode ser trazido por meio de ferramentas como a participação popular, na medida da busca de efetivação dos direitos sociais, por exemplo. Essa busca de efetivação pode ser feita mediante atuaçôes que buscam efetivação da cidadania pela "participação política nos destinos do Estado, seja pelos meios mais diferente possíveis: associaçôes comunitárias, conselhos de discussão de políticas públicas, etc.”. (CRUZ, 2008, p. 22).

No entanto, a sociedade civil é composta por diversos atores com demandas distintas e nem sempre diretamente relacionadas. Dessa forma, o primeiro passo para compreender formataçôes de controle é compreender a essência interna do corpo social. De forma que, a participação formal de indivíduos em estruturas institucionalizadas pode não ser o formato

1 Art. 10 A República Federativa do Brasil, formada pela uniáo indissolúvel dos Estados e Municípios e do Distrito Federal, constitui-se em Estado Democrático de Direito e tem como fundamentos: I - a soberania; II - a cidadania; III - a dignidade da pessoa humana; IV - os valores sociais do trabalho e da livre iniciativa; V - o pluralismo político. Parágrafo único. Todo o poder emana do povo, que o exerce por meio de representantes eleitos ou diretamente, nos termos desta Constituição. (grifo nosso).

2 Convém ressaltar que a postulaçấo de direitos pelo povo é condição intrínseca ao processo democrático, como forma de fomentar as demandas provenientes destes (e não necessariamente de seus representantes), uma vez que "democracia designa o sentido de permanente ampliação dos espaços de emergência de novas liberdades e novos direitos, como obra inconclusa” (SOUSA JUNIOR, 2008, p. 256) devendo, assim, se manter aberta para acompanhar as mudanças sociais. 
democrático mais efetivo no Brasil para representar essa diversidade 3 . Uma vez que há uma falta de representatividade entre quem se encontra no poder e as necessidades reais dos sujeitos de direitos, verifica-se a:

[...] ausência da participação popular por meio deseus representantes eleitos, pela própria cultura brasileira, que teve adormecida dentro da massa social o espírito pedagógico do ingresso nas deliberaçóes pertinentes à vida do Estado e da comunidade, propiciou de tal modo a consolidação dos movimentos sociais sejam eles quais forem sua demandas, como elementos estimuladores de uma cidadania ativa, náo dada, mas, conquistada. (CRUZ, 2008, p. 25).

A noção de participação como forma mais integradora poderá, dessa forma, abranger como elemento "o movimento de indivíduos, grupos, organizaçóes que expressam interesses, valores e identidades que buscam 'fazer ou tomar parte' do processo político-social, a partir de suas particularidades" (SOUZA FILHO, 2017, p. 03) como complementação às opções de diálogo dentro de instituições públicas.

Nesse sentido, afirma-se que presença de movimentos sociais pode ser vista como necessária para exercício de um controle ativo que vá de encontro ao tecnicismo ${ }^{4}$ presente em processos organizados por procedimentos cada vez mais burocráticos, que produzem uma espécie de linguagem inacessível ao cidadão comum (ALVES, 2013, p. 129) lhe renegando a possibilidade direcionada e institucionalizada de buscar seus direitos. Funcionando, dessa forma, como espaço aberto a ouvir as vozes dos atores e suas demandas de forma mais abrangente e participativa.

Indo além da possibilidade de ser ouvido, as movimentaçóes de grupos fluem como processo de participação que abrem espaço não só para pedir a efetivação do que já foi estipulado nas legislaçôes, mas também criar novos direitos e quebrar paradigmas sociais estagnados, de forma que

o fio condutor da participação popular começou a divisar um projeto de organização de direitos e liberdades fundamentais, de instrumentos e de mecanismos eficazes para a garantia desses direitos e liberdades básicos e, sobretudo, a constituir os novos sujeitos autores autônomos deste processo. (SOUSA JUNIOR, 2008, p. 262) (grifo nosso).

Logo, a formação de processos democráticos participativos envoltos em movimentos sociais representa a abertura de uma nova postura transformadora que almeje não só a busca e efetivação de direitos fundamentais já existentes no texto constitucional ${ }^{5}$, mas também

3 Apesar disso, não se pode deixar de reconhecer a importância de toda e qualquer forma de participação popular, uma vez que as ferramentas existência defendem a própria soberania do povo e garantem "o funcionamento legítimo das instituiçóes democráticas do Estado de Direito, a fim de superar as desigualdades materiais estruturais da sociedade brasileira" (FACHIN, 2006, p. 51)

4 Nesse mesmo sentido, afirma Sousa Junior (2008, p. 262) que "os movimentos sociais instauram um novo espaço público onde a sociedade passa a ouvir suas mensagens e traduzir as reivindicaçóes em tomada de decisão política, em com isso perder a autonomia conquistada no processo de luta"

5 "[...] importa é que o exercício do controle social esteja o mais possível vocacionado à universalização e à ausência de tudo que embarace a livre e fundamentada prática do discurso constitucional.” (FREITAS, 2009, p. 412). 
abrir espaço para a possibilidade de mudanças sociais e resolução de conflitos estruturados e reproduzidos pelas instituiçóes.

\section{Movimento feminista como formador de novas posturas sociais e controle social das opressóes patriarcais}

Há então a possibilidade apontar movimentos sociais como direcionadores de, não só alcance de direitos formalizados e não formalizados perante o Estado, como também como possíveis formadores de posturas sociais distintas diante de crises e quebras de paradigmas.

Como exemplo disso pode-se apontar as nuances desenvolvidas pelo movimento feminista como detentor dessas características, e indo além, na busca pela efetiva libertação de gênero.

No Brasil, a evolução do movimento feminista teve como grandes nomes Nísia Floresta e Bertha Luz ${ }^{6}$ ganhando espaço nos anos 60 e 70, influenciadas diretamente pelo movimento feminino inglês (MIGUEL, BIROLI, 2014, p. 29). Claro que inicialmente, tal qual o movimento sufragista inglês as primeiras questôes foram a de efetivar o direito ao voto para as mulheres - que já era um ato jurídico preexistente para homens - no Brasil, fato este que só foi alcançado através após a Revolução de 1930.

No entanto, dado o alcance de poder escolher representantes formais, abriu-se espaço para a intenção feminina de possuir representaçôes também nas políticas de acesso a outros direitos ainda não garantidos às mulheres, uma vez que foi possível observar que "Em diversos setores da vida social brasileira, estabeleceram-se [...] verdadeiros hiatos entre as relaçóes sociais efetivas e a sua regulamentação jurídica" (SAFFIOTI, 2013, p. 357).

Dessa forma, o movimento feminista fortaleceu seu direcionamento para a elaboração de legislações necessárias para defesa da população feminina (SAFFIOTI, 2013, p. 357), pugnando a favor dos direitos reprodutivos, trabalhistas e pela proteção contra violências sofridas, já que

A conquista do voto, em 1932, não significou para as mulheres uma mudança substancial nos valores sociais então vigentes, uma vez que estas continuaram submetidas a uma estrutura patriarcal conservadora e a um modelo de cidadania que privilegiava o espaço público como reduto masculino. (FERREIRA, 2004, p. 22)

Esse direcionamento inaugurou a possibilidade de protagonismo da mulher como um sujeito político que luta pela aplicação de políticas públicas validadoras dos seus direitos ${ }^{7}$. De forma a se desenvolver uma democracia redistributiva, isto é, "capaz de assegurar, de modo eficaz, a inclusão das minorias/ grupos vulneráveis" (ALVES, 2013, p. 127).

6 Bióloga, fundadora da Federação Brasileira pelo Progresso Feminino (FBPF), organização que despontou campanha pública para a conquista do direito ao voto como pauta essencial para a conquista da cidadania feminina, que se efetivou em 1932, com a promulgaçáo do Novo Código Eleitoral Brasileiro.

7 Conforme Amâncio (2013, p. 04) "[...] a ascensão das questôes femininas no meio público proporcionou maior visibilidade para as mulheres e para os movimentos engendrados por elas. Assim, a politização das questóes femininas permitiu "um olhar mais de perto" acerca do processo de redemocratização da sociedade [...]". 
Tal inclusão foi buscada pelas mulheres na tentativa de serem ouvidas e terem alcance do seu espaço na sociedade, de forma que essa “[...] emancipação feminina contribuiu expressivamente para a projeção das mulheres no espaço público bem como para uma tomada de poder por meio da formação política nos movimentos femininos." (AMÂNCIO, 2013, p.03).

Dois grandes exemplos na história do movimento com atuação de forma prática no controle (e busca) de políticas públicas para mulheres são os representados pela Federaçáo Brasileira pelo Progresso Feminino (FBPF) e pela criação do Conselho Nacional De Direitos Da Mulher (CNDM), este último com força atuante na própria assembleia constituinte de 1988 "juntamente com os movimentos de mulheres e feministas, reivindicando a inclusão de mais direitos das mulheres na nova Constituição" (AMÂNCIO, 2013, p. 05).

Assim, os movimentos se mostram como uma forma de luta e resistência frente a um padrão de produção de leis por homens que legislam a favor da população masculina, uma vez que existirá uma interação entre movimento e Estado, na qual poderá se "identificar uma mútua influência em suas agendas [refletindo] reciprocamente em legitimidade pública para a temática sobre mulher e gênero na arena política” (MARIANO;GALVÃO, 2014, p. 83).

Ademais, diante dessa possibilidade se fazer protagonista, abre-se para a mulher a capacidade de exercício do controle social que busque a criação de novos direitos e a quebra de paradigmas sociais patriarcais, dessa forma:

Não há dúvida de que o movimento feminista brasileiro [...] desempenhou relevante papel no que diz respeito ao despertar da consciência da mulher não apenas para os seus problemas, como também para todos os problemas do mundo moderno que, em última instância, a afetam direta ou indiretamente [e] inoculou, em boa parcela das mulheres, a aspiração de libertar-se e de emancipar-se [...] processo este que foi amadurecendo à medida que, efetivamente, iam os elementos femininos penetrando em áreas até então reservadas exclusivamente aos homens. (SAFFIOTI, 2013, p. 382).

Assim, desvela-se que o movimento feminista, para além de uma forma de controle social feminino pela busca de seus direitos, tornou-se formador de nova postura da mulher, agora militante e protagonista na luta por ocupar espaços relegados apenas aos homens.

\section{Feminismos como força motriz para a efetivação da justiça social de gênero}

Diante da força do movimento feminista em quebrar paradigmas, vê-se um novo horizonte na luta por açóes desconstituidoras de dicotomias de gênero ${ }^{8}$ estabelecidas socialmente e institucionalmente para se ter uma real efetivação da cidadania feminina.

Uma vez que se tem uma sociedade desigual, desenvolvida sob o manto do patriarcado, a construção da mulher no seio social vai além do papel do seu sexo por si só, abrangendo

8 A definição dicotômica é criada pelo patriarcado como inamovível, nele a mulher fica presa ao âmbito doméstico, onde este se torna uma ferramenta para manter a dominação masculina por meio da naturalização da domesticidade feminina e tratamento de comportamentos distintos do definido como "desvios" (MIGUEL; BIROLI, 2014, p. 32). 
condiçôes vinculadas à própria estrutura econômica da sociedade (BEAUVOIR, 2016, p. 83). A qual, considerando a realidade brasileira é tomada por uma:

[...] ordem cultural [...] institucionalmente diferenciada, em que uma multiplicidade de instituiçôes regula uma multiplicidade de arenas de ação segundo padrões distintos de valores culturais. Nossa sociedade também tem uma ordem cultural eticamente pluralista, em que nem todos os membros compartilham um horizonte de avaliação comum, uniformemente difuso. (FERREIRA, 2010, p. 03)

E no que se refere à condição social feminina e seu espaço na ordem cultural social, não há apenas uma "diferença". A posição social feminina é vinculada a uma inferioridade, possuindo menos acesso a espaços de poder e controle de bens materiais (MIGUEL; BIROLI, 2014, p. 102), o que numa sociedade capitalista significa não ser e nem ter direito a nada.

Pode-se inferir que o que feminismo busca - por meio de suas diversas vertentes ${ }^{9}$ - é trazer força para enfrentar as desigualdades subjetivas dentro da pluralidade de mulheres, atacando as bases capitalistas que buscam manter o "entrelaçamento de obtenção de lucro com produção de pessoas e sua subordinação da segunda à primeira" (ARRUZZA; BHATTACHARYA; FRASER, 2019, p. 119).

A visão que se desenvolve dessa análise é que, assim como outros movimentos sociais, o movimento feminista se renovou, indo além de uma 'queda de braços' com partes tida como opostas, passando a se preocupar com a verdadeiras mudanças estruturais na sociedade (MADALENA, 2016, p. 129) na intenção de quebrar paradigmas, padrôes e opressôes. ${ }^{10}$

Interessante ressaltar que essa nova forma de buscar efetividade para os direitos femininos acabam garantindo não só os direitos das mulheres, especificamente, mas também um maior desenvolvimento social como um todo. Uma vez que, conforme explica Sen (2000, p. 235):

[...] A condição de agente das mulheres é um dos principais mediadores da mudança econômica e social, e sua determinação e suas consequências relacionam-se estreitamente a muitas das características centrais do processo de desenvolvimento.

Mas, é importante considerar que a capacidade de ser considerada agente ativa social pelos seus direitos é ainda uma luta constante para mulher. Visto que diante das relaçóes sociais ainda é preciso distinguir e esclarecer o que realmente está significando ou não a aceitação dos novos papéis vivenciados pelo público feminino ou quais são as técnicas sociais que possivelmente estão reproduzindo e mantendo preconceitos (SAFFIOTI, 2013, p. 392).

Um exemplo que pode ser relacionado à essas técnicas é o Estatuto da mulher, que apesar de ter sido uma grande revolução para a discussão dos direitos da mulher no âmbito público, ainda sim, abria margem para a manutenção das exclusôes. Conforme Heleieth Saffioti (2013, p.

9 Ainda que possuam diferentes pontos de vista e diferenças internas nos subgrupos feministas, existem entre eles pontos de convergência que somados formam os pilares da identidade do movimento feminista - seja como movimento social ou teoria intelectual - com um mesmo núcleo fixo de princípios norteadores e reinvindicaçôes fundamentais (MADALENA, 2016, p. 136)

10 "[...] A luta pode aprofundar nossa compreensão sobre a própria opressão - o que a causa, quem se beneficia dela e o que pode ser feito para superá-la" (ARRUZZA; BHATTACHARYA; FRASER, 2019, p. 94) 
371), um exemplo dentro dele, é o fato de ter fornecido "subsídios às justificativas empresariais dos baixos salários e do desemprego feminino, legitimando um comportamento por parte dos empregadores que o feminismo visava a destruir [...]”.

Esse reforço de exclusões se dá pela dificuldade de o sistema capitalista atender demandas plurais e diversas, o que implica numa ofensa à própria democracia - uma vez que o seu núcleo está no atendimento ao pluralismo igualitarista, o qual é:

organizado sob a primazia da igualdade e que conta com diversos atores sociais, inclusive com o Estado, cujos protagonistas constituem subjetividades históricas específicas [e] a proteção a grupos vulneráveis é uma de suas decorrências mais naturais. (ALVES, 2013, p. 127)

Nesse sentido, as questóes trazidas pelo movimento feminista e seus feminismos, dentro da abrangência de pautas específicas de grupos diferentes de mulheres, é algo que os poderes democráticos devem entender como um dever para corrigir injustiças em todas as dimensóes (FRASER, 2009, p. 32) para assim se efetivar, de forma a abraçar as desigualdades de gênero como um problema coletivo, a chamada democracia substantiva garantindo maior inclusão social (ALVES, 2013, p. 133).

Para isso, é preciso aplicar o que Nancy Fraser chama de estratégias transformadoras, que são propostas embasadas em uma transfiguração dos estereótipos de gênero ${ }^{11}$. e não de confirmação como a maioria das açóes afirmativas. Uma vez que, indo ao contrário dessa posição, ratificando tais estereótipos performáticos estipulados em dicotomias patriarcais, gerase ineficácia da própria ação afirmativa

Enquanto as primeiras [açôes afirmativas] visam 'corrigir resultados iníquos dos arranjos sociais sem perturbar as estruturas sociais subjacentes que os geram', as segundas [estratégias transformadoras] objetivam exatamente 'reestruturar o quadro generativo subjacente" (MIGUEL; BIROLI. 2014, p. 105)

Logo, o que se vê é que os movimentos sociais, aqui abordados sob a ótica do movimento feminista, buscam efetivar demandas de igualdade como forma proteção da própria carta constitucional, controlando as açóes e omissóes estatais quantos aos direitos previstos, mas também alcançar uma justiça social pela mudança nas raízes do que gera a desigualdade inicial.

\section{Consideraçóes finais}

O controle social é um dos tipos de controle que o Estado pode - e deve - passar para que as políticas e ações sejam mais equânimes e justas para efetivação de direitos sociais.

11 Já que "as ações afirmativas são relativamente capazes de alcançar esse objetivo, pois a sua direção está muito mais focada em redistribuição - esperando que a partir daí resolvam-se os problemas de reconhecimento - do que propriamente ela ataca diretamente o problema do reconhecimento das diferenças culturais. Essa, portanto, é a ponderação que devemos fazer nesta relação entre a teoria de Fraser e as açóes afirmativas no intuito de acabar com as desigualdades sociais" (FERREIRA, 2010, p.13) 
Existem meios relacionados diretamente à interação cidadáo-instituição para a realização desse controle. No entanto, além dessas, pode-se observar a participação popular por meio de uso da voz e com capacidade de chamar a responsabilidade estatal para as demandas sociais mediante a existência e atuação dos movimentos sociais.

Eles representam de forma mais evidente a possibilidade de todo e qualquer cidadão, em grupos organizados e com interesses específicos, buscarem a atuaçáo do estado em determinada política para que seja implementada ou rechaçada.

Esse formato de controle se molda ao que se conhece de democracia participativa e sai da esfera da burocracia que limita a atuação do cidadão frente às instituiçôes, afirmação sua cidadania.

Como exemplo para a análise realizada foi apontado o movimento feminista como movimento social, construído em lutas de reconhecimento da mulher como sujeito de direitos constitucionais e também modelo de controle exercido pelas mulheres. No Brasil, inclusive, se mostrando capaz de atuar diretamente na própria formulação da carta constitucional na busca de garantir e efetivar direitos após a redemocratização.

De forma que o movimento se caracteriza como ferramenta de controle da mulher sobre as políticas que foram ou não estipuladas ao público feminino, considerando-se a questôes de gênero pelos gestores.

Observa-se que, além disso, o movimento tem um teor revolucionário para além da formalização de direitos e políticas. O poder que a participação popular - aqui exemplificada pelos feminismos e movimentos de mulheres - se mostra como uma superação também de construçôes dicotômicas e excludentes.

Tais construçôes podem ser observadas muitas vezes na lei, nas políticas realizadas, mas também estão enraizadas no meio social. Dessa forma, a atuação do movimento representa a possibilidade de elevação do protagonismo da mulher e uma crítica a políticas afirmativas que apenas reafirmam as desigualdades, buscando-se na verdade a efetivação de transformaçóes sociais, como forma de desenvolver a mulher como cidadã e assim toda a sociedade em conjunto, por meio da identificaçáo e resolução do que gera a desigualdade pela raiz.

\section{Referências}

ALVES, Fernando de Brito. Constituição e participação popular: a construção históricodiscursiva do conteúdo jurídico-político da democracia como direito fundamental. Curitiba: Juruá, 2013.

AMÂNCIO, Kerley Cristina Braz. "Lobby do Batom”: uma mobilização por direitos das mulheres. In: Revista Trilhas da História. Três Lagoas, v.3, no5 jul-dez, p.72-85, 2013. 
ARRUZZA, Cintia; BHATTACHARYA, Tithi; FRASER, Nancy. Feminismo para os 99\%: um manifesto. Tradução Heci Regin Candiani. 1 ed. São Paulo: Boitempo, 2019.

BRASIL. Constituição da República Federativa do Brasil, promulgada em 05 de outubro de 1988. Brasília/DF: Senado Federal, 1988.

FACHIN, Luiz Edson. Povo e poder reformador: premissas de legitimidade. Argumenta Journal Law, Jacarezinho - PR, n. 6, p. 42-54, fev. 2013. ISSN 2317-3882. Disponível em: <http://seer.uenp.edu.br/index.php/argumenta/article/view/57/57>. Acesso em: 05 jun. 2019.

FERREIRA, Wallace. Justiça e reconhecimento em Nancy Fraser: interpretação teórica das açôes afirmativas no caso brasileiro. Disponível em: <https://www.cp2.g12.br/ojs/index. php/PS/article/download/606/519> Acesso em: 27 mai. 2019.

FRASER, Nancy. O feminismo, o capitalismo e a astúcia da história. In: Mediaçóes, Londrina/PR, v. 14, n.2, p. 11-33, Jul/dez. 2009.

FERREIRA, Maria Mary. Representação feminina e construção da democracia no Brasil. Disponível em: <https://www.ces.uc.pt/lab2004/inscricao/pdfs/painel29/MAryFerreira. pdf> Acesso: 15 jun. 2019.

FREITAS, Juarez. O controle dos atos administrativos e os principios fundamentais. 4. ed., São Paulo: Malheiros, 2009.

MARIANO, Silvana Aparecida; GALVÃO, Elaine; CARLOTO, Cássia Maria (orgs.). Gestão de politicas públicas de gênero: uma experiência de formação de gestores/as locais. - Londrina: [s.n.], 2014.

MIGUEL, Luis Felipe; BIROLI, Flávia. Feminismo e politica: uma introdução. 1. ed. São Paulo: Boitempo, 2014.

SAFFIOTI, Heleieth Iara Bongiovani. A mulher na sociedade de classes. 3. ed. - São Paulo: Expressão Popular, 2013.

SARLET, Ingo Wolfgang. A eficácia dos direitos fundamentais: uma teoria geral dos direitos fundamentais na perspectiva constitucional. 10 ed. rev. atual. e ampl. 3. tir. Porto Alegre: Livraria do advogado Editora, 2011.

SEN, Amartya. Desenvolvimento como liberdade. São Paulo: Companhia das Letras, 2000.

SOUSA JUNIOR, José Geraldo de. Direito como liberdade: o direito achado na rua experiências populares emancipatórias de criação do direito, 2008, 338 f. Tese (doutorado em direito), Faculdade de Direito da UNB, 2008. 
SOUZA FILHO, Rodrigo de. O controle social como instrumento político na gestão do orçamento público. Disponível em: <http://www.uel.br/eventos/orcamentopublico/ pages/arquivos/III\%20SIMPOSIO/O\%20controle\%20social\%20como\%20 instrumento\%20politico\%20na\%20gestao\%20do\%20orcamento\%20publico $\% 20$. pdf> Acesso em: 20 mai. 2019. 